\title{
COMMUNICATION
}

\section{Chinese Mathematics and ICCM}

Editor's Note: Notices invites occasional contributions, such as this piece, from its sister publications.

\section{Lizhen Ji}

\section{Introduction}

China is big and growing, and Chinese mathematics is also expanding and merging with world mathematics. What is special about the community of Chinese mathematicians? How has Chinese mathematics evolved and interacted with the outside world? How will it impact the future of mathematics and the global mathematics community in the world?

Though these questions are complex, one good way to understand them is to take a look at an organization which represents Chinese mathematicians and their friends and collaborators around the world: the International Congress of Chinese Mathematicians (ICCM), which holds its seventh international conference this August in Beijing.

\section{A Glimpse at the History of Chinese Mathematics}

China has a long history, and Chinese mathematics also has a long history. Though Chinese mathematics was directly motivated by applications in astronomy, agriculture, and commerce, there were systematic expositions of theories and results developed by Chinese people. The most famous is the book Nine Chapters on the Mathematical Art.

Since mathematics was not emphasized as a subject by itself in China, mathematics developed slowly, and it reached its peak, the golden age of Chinese mathematics, in the thirteenth century. Unfortunately, Chinese mathematics paused or even declined after that, while the West was moving forward rapidly thanks to the Renaissance, the Age of Enlightenment, and the Industrial Revolution.

The gap between China and the West was wide at the beginning of the twentieth century. Shortly after that, several brilliant Chinese mathematicians emerged on the world stage of mathematics: S. S. Chern, L. K. Hua, W. L. Chow, C. C. Lin, and P. L. Hsu. They built a bridge across the gulf between Chinese mathematics and Western mathematics. Visits to China of several

Lizhen Ji is professor of mathematics at the University of Michigan and an editor for Notices of the International Congress of Chinese Mathematicians. His email address is $1 \mathrm{j} i @ u m i \mathrm{ch}$. edu.

For permission to reprint this article, please contact:

reprint-permission@ams.org.

DOI: http://dx.doi.org/10.1090/noti1402 distinguished Western mathematicians such as Wiener, Hadamard, Blaschke, and Osgood were crucial for their success.

Modern Chinese mathematics reached another minor golden age in the 1950s and early 1960s. Then political turmoil settled in.

\section{The History of ICCM}

With the open door policy in the 1980s, the Chinese economy and hence Chinese mathematics and sciences

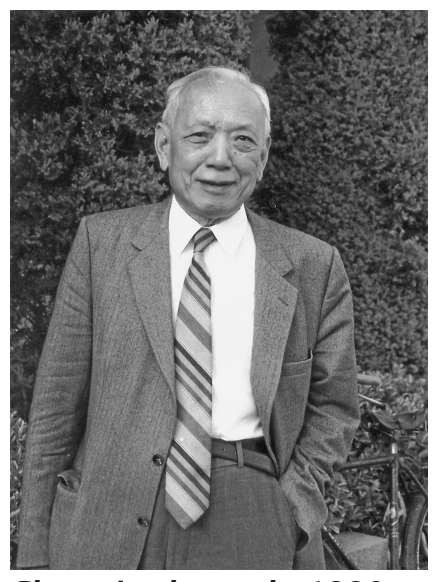
Chern in the early 1990s. developed rapidly. By the 1990s the time was ripe to establish an international platform for mathematicians of Chinese descent and their friends to share and exchange their achievements and ideas. The International Congress of Chinese Mathematicians was established in 1998.

The first ICCM was held in Beijing on December 12, 1998. It has been held every three years since then: 2001 in Taipei, 2004 in Hong Kong, 2007 in Hangzhou, 2010 in Beijing, and 2013 in Taipei. In 2016 it will return to Beijing for the 7 th ICCM.

The invited talks of ICCM consist of plenary talks, 45-minute talks, and Morningside Lectures. The idea of the Morningside Lectures is to invite distinguished mathematicians to give lectures which may stimulate research in areas of mathematics that are not strongly represented in China. For example, in 1998 there were thirteen plenary talks, fifty-five invited 45-minute talks, all given by Chinese mathematicians whether they were working in China or outside, and four Morningside Lectures given by distinguished non-Chinese mathematicians R. Borcherds, J. Coates, R. Graham, and D. Stroock.

Similar in format to the International Congress of Mathematicians, the morning of the first day was devoted to awarding the Morningside Medal and the Chern Prize to Chinese mathematicians who have made significant 


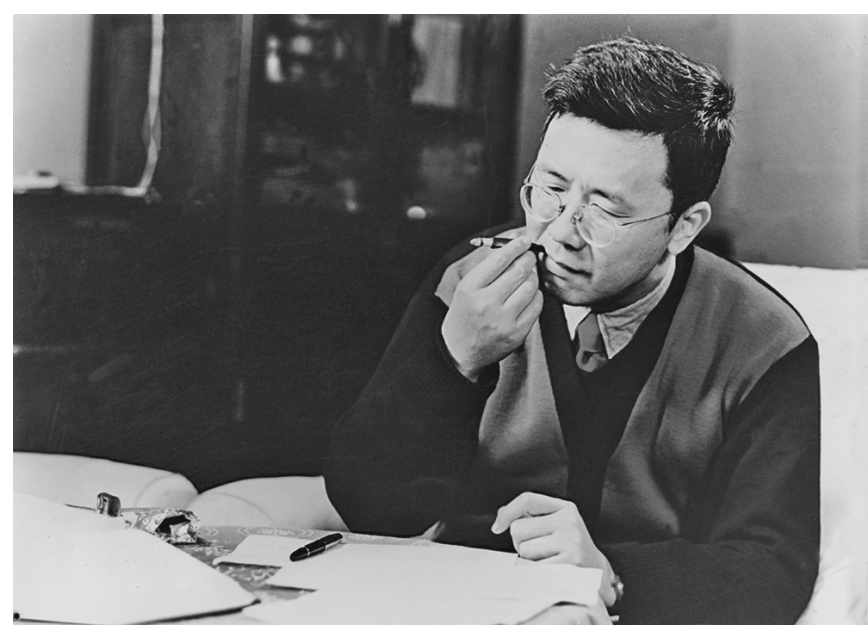

Hua smokes while working (early 1950s).

contributions to pure or applied mathematics. The Morningside Foundation in Hong Kong provided the funding for the Morningside Medals, which are open to people under the age of forty-five. There are other prizes for non-Chinese mathematicians such as the International Cooperation Award.

The first ICCM was attended by more than 400 people, the second by more then 500, the third by more than 800 , the fourth by more than one 1,500 , the fifth by more than 1,600 , and the sixth by more than 800 . It is expected that more than 1,600 people will attend the seventh this August.

\section{The Mission of ICCM}

The mission of ICCM was explained briefly by its president, S. T. Yau, in 1998: "It was a historic event. It was the first occasion where the majority of Chinese mathematicians from all over the world gathered together to present their research. The results and the presentations were spectacular." The key point is to increase the interchange and cooperation between Chinese mathematicians. This is also the guiding principle of the Morningside Center of Mathematics, Beijing, which was es-

\section{What a} jubilant and grand event it was! tablished in 1996 and whose new building was dedicated during the first ICCM.

The mission of ICCM is perhaps best explained by a Chinese essay written by Yau for the first ICCM. Here is an excerpt followed by more in translation.

$$
\begin{gathered}
\text { 第一届全世界华裔数学家大会献辞 } \\
\text { 丘成桐 }
\end{gathered}
$$

公元一九九八年冬, 华裔数学家, 会于京师, 讲学修睦也。聚三地之精 英, 集九州岛之豪士。四方学者, 同根同心。献明月之章, 传不朽之作, 吁巇乎盛哉!

In the winter of 1998, mathematicians of Chinese descent met in the capital Beijing, giving lectures and collaborating with each other. The elites from the three regions converged, and the giants over the nine states came together. Scholars from four corners, with the same root and the same heart, presented their illuminating papers, and handed down their everlasting work. What a jubilant and grand event it was!

Chinese mathematics originated from the Nine Chapters and prospered in the hands of Chern and Hua. Liu made notes for the Nine Chapters, Zu cut the circle, Chern produced classes, and Hua sieved and added. These are the wisdoms of our ancestors, and they are still the essential lights today. When the Second World War broke out in Europe, China was faced with national calamities. At that time, Sun and Yang cultivated men of ability and virtue in Tianjin and Shanghai, and Jiang and Xiong passed on personal teachings in Tsinghua. Later, they gave lectures in Yunnan and established institutions in the south of the Yangtze River. This fine tradition of passing on wisdom has been carried forward for three generations, and students and old friends of these masters are all over the world now. After leaving China, Chern continued to be an influential leader and nurtured a group of mathematicians overseas. Hua returned to Beijing to save the learning of mathematics from destruction and continue the lineage that had been cut off, eventually accomplishing the great cause in the Mainland. At this time, students of Hua and Xiong got the essence of the theory of numbers, and laid the foundation for complex variables. Students of Su and Feng expounded on the subtle meaning of equations, and initiated the research into computational mathematics. So elegant and outstanding were their achievements that they not only lived up to the standards of the ancestors, but also called for continuation of this heritage. Unfortunately, what followed was ten years of turbulence, which sent tremors across all nine states of China. People from all levels were put to torture. Heaven and Earth were in grief. Fathers and sons, teachers and students, as well as

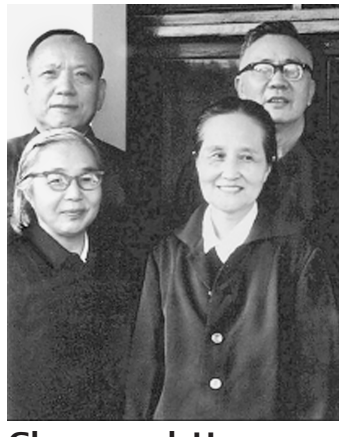

Chern and Hua with their wives at the headquarters restaurant of Beijing Duck, 1972. old friends were forced to take different roads.

The elder did not dare to propose any plan, and the learner did not dare to harbor any ambition. It was after the villain was captured by the General that the nation regained peace. Deng Xiaoping initiated the opening up of China, and from then on, the country has been revitalized.... longing to return, and scholars have come eastward. As a result, virtuous and talented people frequently appear in Taiwan, and achievements are continually made by people in Hong Kong. Both Taiwan and Hong Kong are internationally known for their academic excellence.... 


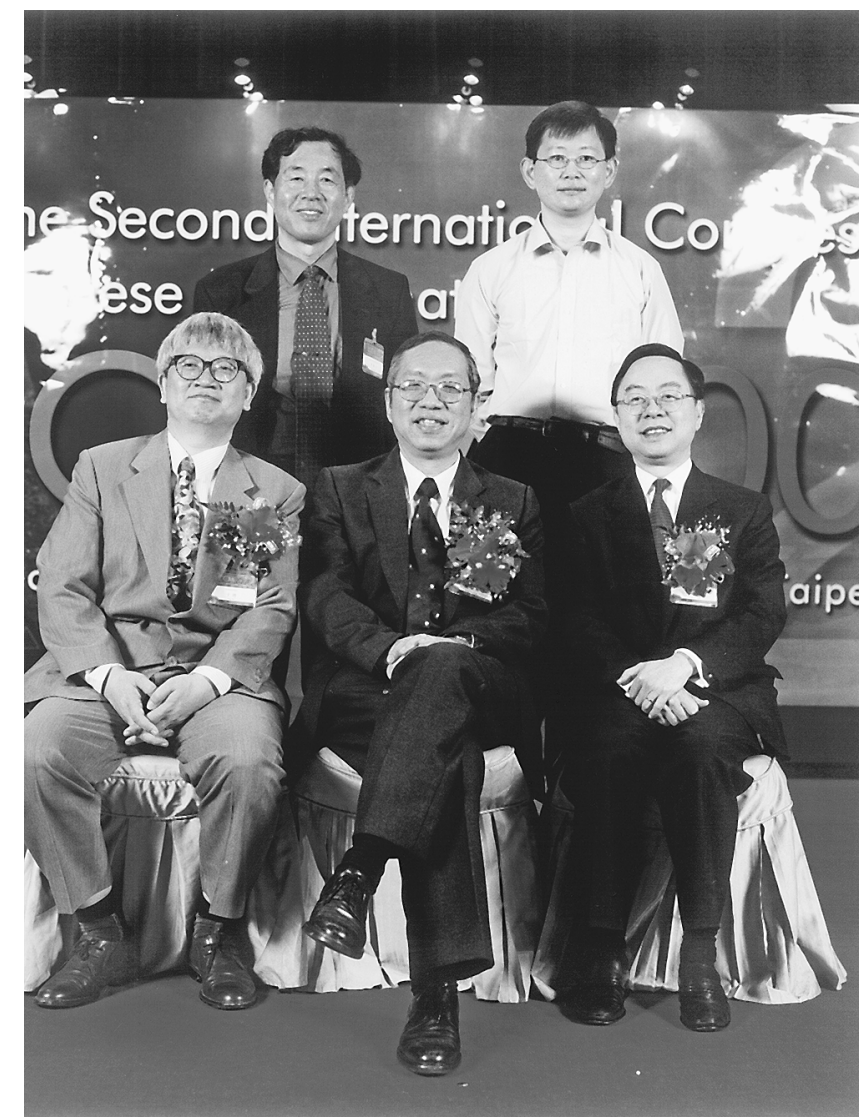

Yau (middle) and donor Mr. Chan (seated, right) with 2011 Chern Prize winners Jiu-koung Yu (seated, left) and Song-Sun Lin (standing, left).

\section{What Has Happened at ICCM?}

The ICCM both facilitates interaction between Chinese and Western mathematics and celebrates major achievements of Chinese mathematicians and their friends.

Much has happened at past ICCMs. Attendees have included representatives of American, European, Japanese, Korean, and Singaporean mathematical societies, as well as such distinguished mathematicians as Gerd Faltings and Peter Lax. Symposia and public talks have covered everything from the effect of technology on Asian economies and challenges facing higher education to the mathematics of gambling and the intersection of math and poetry. The 2007 ICCM in Hangzhou included a panel discussion on women in mathematics.

Awards have been established to recognize mathematics research by high school students; outstanding doctoral, master's, and undergraduate theses; and individuals who have promoted the development of mathematics in China. At the 2013 ICCM in Taipei, a Morningside Special Achievement Award in Mathematics was presented to Yitang Zhang for his breakthrough on the twin prime number problem, and the International Cooperation Prize was awarded to Jean-Pierre Serre.

From the beginning the ICCM has been expertly organized. The opening ceremony of the first ICCM was held in the Great Hall of the People, which is an hour's drive from the Morningside Center-if there's no traffic. When more than a dozen buses left the Morningside Center bound for the Great Hall on the opening day of the 1998 ICCM, all the traffic lights along the route were green, and congress participants enjoyed a speedy, nonstop ride.

\section{Publications of ICCM}

The main publications of ICCM are the Proceedings and Notices of ICCM. The former gives a faithful record of the scientific activities of each ICCM and also includes pictures of awardees and ceremonies, and the latter provides a platform for mathematicians from all over the world to share their thoughts and ideas on recent major progress in mathematics, issues, and problems facing mathematics.

\section{Impact of ICCM}

ICCM gives an identity to the loose group of mathematicians of Chinese descent around the world and provides a unique opportunity for them to gather together and exchange ideas in mathematics. Such a global interaction is very helpful to everyone, especially to those people coming from places in China that are not well exposed to modern mathematics.

The Morningside Lectures given by many distinguished mathematicians who are not of Chinese descent keep the Chinese mathematicians informed of the most recent developments in mathematics in other parts of the world.

The Morningside Medal and other prizes recognize works of promising young Chinese mathematicians and motivate them to continue their excellent work.

\section{Acknowledgements}

The author would like to thank Ming-Chang Kang, Ka-Sing Lau, Lo Yang, and Jing Yu for valuable information and helpful suggestions. He would also like to thank Song-Sun Lin, Karbel Liu, Yuchan Shang, Y. T. Vickey Sun, Shanping Wang, Hao $\mathrm{Xu}$, Hongwei $\mathrm{Xu}$, and Lo Yang for providing the pictures included in this article.

\section{Credits}

Photo of Lizhen Ji, courtesy of Wei Wu.

All other photos were supplied courtesy of author Lizhen Ji. A reasonable attempt was made on the part of the author to secure credits and permissions for these photos.

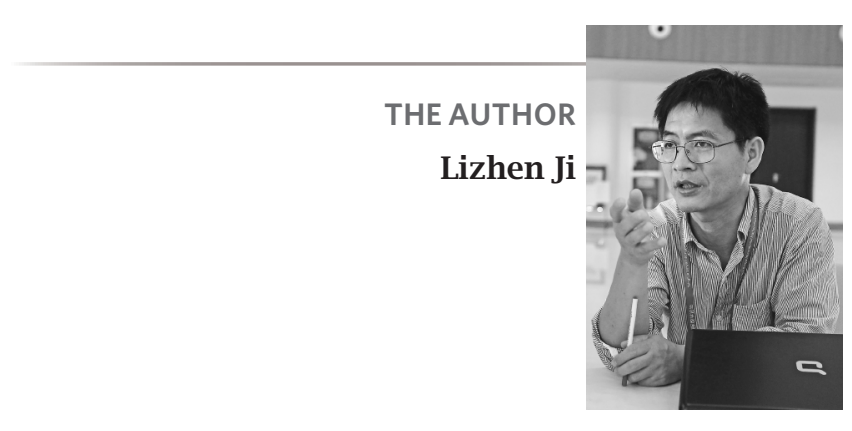

